\title{
A BUSCA POR UMA EDUCAÇÃO PROFISSIONAL E TECNOLÓGICA ALÉM DA FORMAÇÃO PARA O MERCADO DE TRABALHO
}

\author{
Alessandra Acioli Palmeira*; Juliane Costa de França Santos; Paula Danyelle Santana de \\ Andrade \\ *alessandraacioli2@hotmail.com \\ *Instituto Federal de Educação, Ciência e Tecnologia de Sergipe \\ DOI: $10.15628 /$ rbept.2020.10031 \\ Artigo submetido em: maio/2020 e aceito em: jun./2020
}

\begin{abstract}
RESUMO
Este artigo tem como temática central a busca por uma educação profissional tecnológica além da formação mercadológica. Para tanto, os procedimentos metodológicos desta análise estão guiados por estudos bibliográficos. Os fundamentos teóricos se consolidam a partir das concepções do materialismo histórico dialético, da formação omnilateral, do trabalho como princípio educativo e do currículo integrado. Parte-se do pressuposto que o objetivo de uma sociedade com perspectiva de formação omnilateral, segundo Marx, é algo para o futuro. Essa transição requer o domínio dos trabalhadores sobre o conteúdo do seu próprio trabalho, e através da práxis, atuariam na sua realidade transformando-a. Assim, a escola e os seus currículos são fundamentais para a emancipação da classe trabalhadora, na medida em que se comprometam com projetos libertários, baseados no trabalho como princípio educativo. Destarte, o Ensino Médio Integrado, representa um tipo de travessia para a politecnia, por buscar reconstruir a totalidade da realidade através da formação humana integral.
\end{abstract}

Palavras-chave: Ensino Médio Integrado. Formação Humana Integral. Trabalho.

\section{THE SEARCH FOR PROFESSIONAL AND TECHNOLOGICAL EDUCATION IN ADDITION TO EXCLUSIVE TRAINING FOR THE LABOR MARKET}

\begin{abstract}
This article has as its central theme the search for technological professional education in addition to marketing training. For this, a bibliographic research was developed and dialectical historical materialism was used as a theoretical reference. It is assumed that the objective of a society, which has an omnilateral formation perspective, according to Marx, is something for the future. This transition process requires the workers' mastery over the content of their own work, where through praxis, they would act in their own reality, transforming it. Thus, the school and its curricula are fundamental for the emancipation of the working class, insofar as they are committed to libertarian projects, based on work as an educational principle. For this, Integrated High School represents a type of crossing for polytechnic, as it seeks to reconstruct the perception of the totality of reality, through integral human formation.
\end{abstract}

Keywords: Integrated High School. Integral Human Formation. Job. 


\section{INTRODUÇÃO}

Este estudo pretende discutir sobre a busca por uma educação profissional e tecnológica além da formação para o mercado de trabalho. A partir desta premissa acredita-se que a formação voltada para a omnilateralidade terá subsídios para preparar o indivíduo a conquistar sua autonomia, condição na qual ele se reconhece não só como produto da história, mas também como sujeito da sua história, comprometendo-se dessa forma com a transformação social. Estará sendo formado um cidadão para a vida e não apenas para um panorama mercadológico.

Com o objetivo de provocar a reflexão e discussões sobre a significativa abordagem acima mencionada, buscou-se procedimentos metodológicos direcionados pela realização de um levantamento bibliográfico pertinente à temática. Assim, encontrou-se aporte teórico em autores como Ciavatta, Ramos, Moura, Kuenzer, Saviani, Machado, Manacorda, Marx. E assim se consubstanciou o referencial teórico por intermédio das concepções do materialismo histórico dialético, da formação omnilateral, do trabalho como princípio educativo e do currículo integrado.

Nesse entendimento, destaca-se primeiramente a importância da politecnia, já que esta, segundo (SAVIANI, 2003, p. 141) "[...] supõe a articulação entre o trabalho manual e o intelectual," contudo, precisa-se ressaltar que ainda não é possível concretizar a politecnia em sua forma plena para toda a sociedade. Antes, faz-se relevante proporcionar uma formação baseada no princípio educativo do trabalho em "escolas técnicas" focando na "travessia."

Ainda sobre a travessia, de acordo com autores como Frigotto (2011), Ciavatta (2011), Kuenzer (2010), Moura (2011) e Ramos (2005), o Ensino Médio Integrado pode representar um tipo de travessia para a politecnia, indissociabilidade entre trabalho e educação, ou trabalho como princípio educativo, uma vez que pode ser considerado como uma forma de ensino que caminhe no sentido de buscar reconstruir a percepção de totalidade da realidade.

Com a intenção de discorrer sobre os pontos supracitados, este estudo será estruturado por esta introdução; seguido pela seção dois, a qual versará sobre o trabalho como princípio educativo; na sequência virá a seção três, a qual abordará sobre o Ensino Médio Integrado e a formação integral, considerando a relação existente entre as categorias educação e trabalho; e por último virão as considerações finais, as quais chamarão atenção para a construção curricular de forma contextualizada e integradora, capaz de contribuir com o desafio da formação omnilateral. 


\section{O TRABALHO COMO PRINCÍPIO EDUCATIVO E SUAS REFLEXÕES}

O reino da liberdade humana que Marx tanto vislumbrava, configuravase para ele como uma utopia, algo pensado para tempos vindouros. Em outras palavras, quando Marx pensou uma sociedade onde os indivíduos tenham atingido a liberdade, que possam receber uma formação integrada, com bases na politecnia, que sejam sujeitos autônomos, críticos, criativos, capazes de conhecerem sua própria realidade, a realidade social e atuarem sobre ela transformando-a, ele pensou em algo para o futuro, pois acreditava que estas conquistas só seriam possíveis com a queda da burguesia. Para Marx, essa utopia, onde se eliminaria a dicotomia entre teoria e prática, trabalho manual e intelectual, não é impossível, mas requer todo um caminho processual de transição.

O caminho do qual Marx se refere é alicerçado pela práxis, onde a contradição entre capital e trabalho é enfrentada dialeticamente, visando a superação do modelo de produção capitalista. Com este intuito, os trabalhadores necessitam ter domínio sobre o conteúdo do próprio trabalho. A partir dessa perspectiva, segundo Frigotto (2009), "O sentido do trabalho, expresso pela linguagem e pelo pensamento, só pode ser efetivamente real no campo contraditório da práxis e num determinado tempo e contextos históricos". (FRIGOTTO, 2009, p.169).

Dessa forma, será respaldada aqui a categoria trabalho em Marx: "[...] trabalho é um processo entre o homem e a Natureza, um processo em que o homem, por sua própria ação, media, regula e controla seu metabolismo com a Natureza." (1996, p. 297). Assim, o homem "[...] realiza, ao mesmo tempo, na matéria natural seu objetivo, que ele sabe que determina, como lei, a espécie e o modo de sua atividade e ao qual tem de subordinar sua vontade." (MARX, 1996, p. 298). Esse aspecto ressalta o caráter teleológico do trabalho, ou seja, a capacidade de projetar, eminentemente do ser humano. E ainda, o entendimento de Marx por trabalho baseia-se na troca orgânica, recíproca do ser humano com a natureza e a atividade que transforma a matéria natural.

Conforme foi ressaltado acima, o homem ao atuar por meio desse movimento sobre a natureza externa a ele e ao modificá-la, modifica ao mesmo tempo sua própria natureza. Nesse contexto, muito bem apregoa Saviani (1989) "Se é o trabalho que constitui a realidade humana e se a formação do homem está centrada no trabalho, isto é, no processo pelo qual o homem produz a sua existência, é também o trabalho que define a existência histórica dos homens. (SAVIANNI, 1989, p.8).

Faz-se importante salientar, que o processo de trabalho no capitalismo ocorre, a partir da exploração do capitalista sob o trabalho do proletariado. Contudo, as formas de exploração dentro do capitalismo possuem peculiaridades conforme a maneira como está organizada a produção. Ademais, segundo Kuenzer (2007), sob os pilares do regime de acumulação do taylorismo-fordismo há uma ampliação da separação entre teoria e prática, 
como também da oferta de educação destinada aos trabalhadores e às classes dirigentes.

Através da formação dos homens no transcorrer da história, que são trazidas as determinações do modo como produzem a sua existência. É possível destacar, ao longo da história, distintos modos da existência humana, a saber: modo comunitário, o comunismo primitivo, o modo de produção asiático, o escravista e o modo de produção capitalista. Muitas mudanças ocorreram no mundo do trabalho a partir do final da Idade Média, quando se inverte a relação que antes era da agricultura prevalecer sobre a indústria e passa para a indústria prevalecer sobre a agricultura.

Falando-se sobre mudanças, outras significativas também ocorreram a partir da desestruturação do taylorismo/ fordismo e nos encaminhando para a vertente da educação, vê-se a prevalência da pedagogia das competências, baseada numa concepção pragmática, já que os conhecimentos serviam para atender às necessidades do mercado. No Toyotismo houve a necessidade de um trabalhador multitarefa, onde a sua subjetividade foi em demasia aproveitada, porém para continuar atendendo a arrecadação da mais-valia pelos detentores dos meios de produção capitalista. Apesar do operário toyotista participar mais do processo de produção através da sua subjetividade, esta encontra-se estranhada com relação ao que se produz, assim os trabalhadores continuam sendo desvalorizados e oprimidos. Vale ressaltar que apesar do trabalhador subordinar-se, ele é um elemento vivo em constante medição de forças com o capitalismo, gerando oposições e conflitos.

No contexto capitalista, salientam-se evidências notórias na vida cotidiana e como o mesmo pode ser pernicioso, por exemplo, o estímulo ao consumismo. Aqui será aberto um parêntese para se falar sobre um elemento crucial do capitalismo, a mercadoria. É interessante enfatizar o que Marx chama de fetichismo da mercadoria, onde prevalece a ideia de que ela pudesse ter vida própria, como se auto criasse, transmitindo status social a quem a adquire, assim consome-se muito mais pelo desejo do que pela real necessidade. Ou seja, "À primeira vista, a mercadoria parece uma coisa trivial, evidente. Analisando-a, vê-se que ela é uma coisa muito complicada, cheia de sutileza metafísica e manhas teológicas". (MARX, 1996, p.197).

As mercadorias satisfazem necessidades humanas pelas suas propriedades, as quais se constituem produto do trabalho humano e como tal não há nada enigmático enquanto valor de uso. Dessa forma, Marx conclui que o caráter místico das mercadorias não provém de seu valor de uso. Percebese conforme o exposto, quais são os pontos marcantes da sociedade de consumo, onde a base do capitalismo está na contradição entre a socialização do trabalho e a privatização dos meios de produção, porque é aí onde se expressa a contradição entre as forças produtivas e relações de produção, onde o proletariado é explorado gerando riqueza para a burguesia. $O$ proletariado além de trabalhar em demasia e ganhar minimamente, ainda se vê sujeito pelo sistema a consumir desenfreadamente, numa verdadeira bola 
de neve, onde sua alienação é alimentada pela ideologia da classe dominante que perpassa nesse processo.

A letra da música Cidadão de Papelão, vem ilustrar como o capitalismo é pernicioso para àqueles que são dominados: “(...) O cara que catava papelão pediu/ Um pingado quente, em maus lençóis, à sós/Nem farda, nem tão pouco fartura/ Sem papel, sem assinatura/ Se reciclando vai, se vai (...)". (ANITELLI, 2008). O personagem retratado na música vive à margem da sociedade, sem papel, que pode significar papel social ou sem identidade, sem farda, ou seja, sem profissão, sem assinatura, ou seja, sem estudos, a sós, na sua invisibilidade perante a sociedade. Aí está um ser humano, que está longe de exercer a sua cidadania, pois ora submete-se ao capital, ora ao mínimo para a subsistência, em oposição àqueles que ostentam, pois podem ostentar. Existem também aqueles que lutam para parecer que ostentam e finalmente aqueles que não têm nada a ostentar, nem mesmo a dignidade humana. Denota-se daí o entendimento da desconstrução do conceito de trabalho como sendo o que dignifica o homem, já que, nesse sentido, nem todo trabalho dignifica, somente os que trazem reconhecimento e ostentação. E como se dará a superação desse tipo de sociedade com características tão antigas que se arrastam até a atualidade? Savianni comenta sobre o assunto afirmando que "A superação desse tipo de sociedade é que viabiliza as condições para que todos os homens possam se dedicar ao mesmo tempo ao trabalho intelectual e ao trabalho manual". (SAVIANNI, 1989, p.16).

Sobre a formação humana visando ao rompimento da dicotomia trabalho intelectual e manual, segundo Marx, os indivíduos da classe trabalhadora deveriam receber os conhecimentos na área intelectual, física e tecnológica. Gramsci concorda com Marx no sentido de lutar contra a fragmentação do conhecimento e diz ainda que defende uma escola unitária essencialmente humanista, onde a sua base é o tripé: trabalho, cultura e ciência, além de comungarem sobre a indissociabilidade entre trabalho e educação, ou trabalho como princípio educativo.

Nesse contexto, é importante enfocar o conceito de politecnia, derivado do conceito trabalho como princípio educativo, já que "A noção de politecnia se encaminha na direção da superação da dicotomia entre trabalho manual e trabalho intelectual, entre instrução profissional e instrução geral". (SAVIANNI, 1989, p.13). Em se tratando de ensino médio, o trabalho enquanto princípio educativo nesta etapa, visa permitir o entendimento da historicidade da produção científica e tecnológica, conforme os conhecimentos são desenvolvidos e apropriados pela sociedade.

Várias são as possibilidades de ensino e tanto podem servir para projetos libertários ou conservadores, depende da finalidade que oriente sua escolha, seu uso e sua avaliação, ou seja, numa sociedade que é subjugada aos ditames capitalistas, o ensino profissional é destinado àqueles que devem executar, enquanto que o conhecimento científico-intelectual é destinado àqueles que devem conceber e controlar o processo. Apesar do trabalhador dominar algum tipo de conhecimento, trata-se do conhecimento parcelado. $\mathrm{E}$ 
assim, Gramsci esclarece que todos os homens são intelectuais, já que o que conta realmente é a sua colocação no âmbito das relações sociais que vai acarretar uma valorização das profissões mais ou menos intelectuais. Para este autor, "existe em qualquer trabalho físico, inclusive no mais mecânico e degradado, um mínimo de qualificação técnica, isto é, um mínimo de atividade intelectual criativa. (GRAMSCI, apud MANACORDA, 1990, p.151).

Então, para que o conhecimento não seja parcelado, necessita-se de um direcionamento para a formação humana integral. Isto é o que será tratado na próxima seção, esclarecendo a importância de se compreender a proposta de EMI a partir da integração entre os currículos do ensino básico com o ensino específico, porém fugindo de uma simples justaposição entre eles.

\section{A FORMAÇÃO HUMANA INTEGRAL NA PERSPECTIVA DO ENSINO MÉDIO INTEGRADO}

Por meio do Decreto no 5.154/04, assume-se a orientação do Ensino Médio Integrado de integrar o Ensino Médio e o Ensino Técnico de nível médio, tendo como premissa a busca pela articulação educação e trabalho (GRABOWSKI, 2005). Dessa forma, esta etapa

[...] possui um significado e um desafio para além da prática disciplinar, interdisciplinar ou transdisciplinar, pois implica um compromisso de construir uma articulação e uma integração orgânica entre o trabalho como princípio educativo, a ciência como criação e recriação pela humanidade de sua natureza e cultura, como síntese de toda produção e relação dos seres humanos com seu meio. Portanto, ensino integrado implica um conjunto de categorias e práticas educativas no espaço escolar que desenvolvam uma formação integral do sujeito trabalhador. (GRABOWSKI, 2005, p. 9).

Assim, verifica-se a notoriedade dessa etapa de ensino e a busca de práticas educativas direcionadas para uma formação humana integral. Há, portanto, uma necessidade social de se entender a realidade, de se buscar a reconstrução da totalidade, por conta da fragmentação mantida pelo sistema econômico, social e político. Dessa forma, "se a realidade existente é uma totalidade integrada não pode deixar de sê-lo o sistema de conhecimentos produzidos pelo homem a partir dela, para nela atuar e transformá-la" (MACHADO, 2010, p. 50). Por conseguinte, para Kuenzer (2010), faz-se importante 
[...] construir uma proposta de Ensino Médio integrado que supere a mera justaposição dos componentes geral $e$ específico dos currículos, sem cair no engodo de projetos com reduzida sistematização do conhecimento e a negar a necessidade de formação teórica para os trabalhadores, mediante uma rigorosa articulação entre teoria e prática, a partir da prática social e dos processos de trabalho. (KUENZER, 2010, p. 868).

Novamente, ressalta-se a relevância de articulação entre teoria e prática, educação e trabalho, a partir do pensamento de Ciavatta (2014), o qual aborda a formação integrada não somente como uma articulação entre o ensino básico e o específico, mas associado com a concepção da formação politécnica. A proposição desse tipo de formação é caracterizada pela luta contra a dualidade estrutural da educação brasileira, em busca da concretização da democracia. A autora afirma também que:

[..] tornar íntegro, inteiro, o ser humano dividido pela divisão social do trabalho entre a ação de executar e a ação de pensar, dirigir ou planejar. Trata-se de superar a redução da preparação para o trabalho ao seu aspecto simplificado, escoimado dos conhecimentos que estão na sua gênese científico-tecnológica e na sua apropriação histórico-social. (CIAVATTA, 2012, p. 84).

Ao tratar sobre o EMI, é fundamental compreender que este corresponde a uma integração entre os currículos do ensino básico com o ensino específico, porém foge de uma simples justaposição entre eles. Conforme Ramos (2010):

Não se trata de somar os currículos e/ou as cargas horárias referentes ao ensino médio e às habilitações profissionais, mas sim de relacionar, internamente à organização curricular e do desenvolvimento do processo de ensino-aprendizagem, conhecimentos gerais e específicos; cultura e trabalho; humanismo e tecnologia (RAMOS, 2010, p. 51-52).

Percebe-se que a justaposição de conteúdos gera uma confusão e a consequente superposição de disciplinas, que sequer dialogam com os conteúdos. Isto ocorre devido a uma hierarquização dos conhecimentos, ou seja, uns são vistos como mais relevantes que outros e são abordados de forma fragmentada. Portanto, nota-se que as disciplinas necessitam estar conectadas para que as atividades propostas nas salas de aula sejam 
significativas. Para isso, os alunos precisam compreender a relação entre as disciplinas e conteúdo, por exemplo, perceberem que todos os conhecimentos vivenciados na escola são ângulos diferentes de uma mesma e única realidade. Apesar de cada conhecimento parecer autônomo e autossuficiente, na verdade só pode ser compreendido em sua totalidade como parte de um conjunto. vinculado

Por isso se faz imprescindível que o currículo esteja efetivamente [...] à vida dos educandos, à dinâmica da interação e dos processos históricos, sociais, econômicos e culturais relevantes que estes vivenciam. Elementos significativos do passado, que precisam se integrar aos fatos cruciais do presente. Elementos do conhecimento empírico e da cultura que trazem os educandos a partir de suas experiências de vida, que precisam juntar-se aos conhecimentos científicos para significá-los. (MACHADO, 2005 p. 53).

É salutar ter clareza que almejar o Ensino Médio Integrado não deve ser a atividade fim. Nos ditames de uma sociabilidade capitalista, é inviável uma escola que consiga atender e cercear a dualidade da oferta de ensino. Em contrapartida, "a superação desse tipo de sociedade é que viabiliza as condições para que todos possam dedicar-se, ao mesmo tempo, ao trabalho intelectual e ao trabalho manual." (SAVIANI, 2003, p. 139). Assim, é preciso perceber que "[...] a politecnia supõe a articulação entre o trabalho manual e 0 intelectual." (SAVIANI, 2003, p. 141). Complementando ainda com Saviani, a defesa da politecnia pressupõe o domínio dos fundamentos científicos, assim como a técnicas que utilizadas no processo de trabalho.

Então, o Ensino Médio Integrado, pode ser considerado como uma forma de ensino que caminhe no sentido de buscar reconstruir a percepção de totalidade da realidade. Logo, como foi mencionado na introdução deste estudo, alicerçados nas ideias defendidas por autores como Frigotto (2011), Ciavatta (2011), Kuenzer (2010), Moura (2011) e Ramos (2005), essa etapa pode representar um tipo de travessia para a politecnia.

No tocante ao currículo integrado, é válido levar em conta a vida dos educandos com todas as dimensões existentes, pois suas vivências históricas, sociais, econômicas e culturais precisam ser ressignificadas a partir da realidade atual. A respeito dessa concepção de currículo integrado à vida dos educandos, temos elementos significativos do passado, que precisam integrarse aos fatos cruciais do presente. Elementos do conhecimento empírico e da cultura que trazem os educandos de suas experiências de vida que precisam juntar-se aos conhecimentos científicos para significá-los (MACHADO, 2010, p.82). 
Precisa-se considerar também que nessa integração, os conteúdos gerais e técnicos possuem a mesma importância nesse processo de formação. Sendo assim, para Machado (2010, p. 82) deve haver "uma ruptura com um modelo cultural que hierarquiza os conhecimentos e confere menor valor e até conotação negativa àqueles de ordem técnica". Para o referido autor, essa integração curricular significa também como momento propício para os profissionais envolvidos, superarem as fragilidades de cada tipo de ensino (médio e técnico) e buscarem outras relações entre teoria e prática.

Para tanto, é relevante que haja uma sistematização de ações integradas, cuidando de não privilegiar qualquer disciplina ou conteúdo específico, uma vez que o essencial é despertar as potencialidades do educando para que ele assuma um papel de agente transformador. Assim,

[...] faz-se necessário selecionar e organizar conteúdos que viabilizem o conhecimento da realidade vivida e das experiências desses sujeitos, que reafirmem seu potencial de protagonistas da história e da cultura. O processo educativo da modalidade do ensino integrado pode, para tanto, recorrer a propostas de ação didática que dialoguem e contribuam para o desenvolvimento de formas organizativas de alunos e professores que sejam instâncias mediante as quais possam contribuir para intervir na realidade social em que vivem. (MACHADO, 2010, p. 89).

A partir das reflexões trazidas nesta seção, depreende-se em suma, que - Ensino Médio Integrado busca o trabalho como princípio educativo, a educação como atividade humanizadora, capaz de desenvolver as potencialidades humanas de forma integral, o ser humano e não o mercado de trabalho como centro do processo educativo e o desvio da dualidade entre educação propedêutica e educação profissional.

\section{CONSIDERAÇÕES FINAIS}

Imprescindível destacar que, na escola, a construção do seu currículo é fundamental na luta pela autonomia e emancipação dos indivíduos. O currículo servirá a este fim, à medida em que através de uma visão ético política estiver voltado para o comprometimento com a classe trabalhadora. Nesse currículo, os conteúdos escolhidos deverão ser contextualizados com a realidade social, voltados para a interdisciplinaridade e comprometidos com a transformação social, na busca pela formação do homem omnilateral. Para tanto, Gramsci (1990), assevera que "O advento da escola unitária significa o início de novas relações entre trabalho intelectual e trabalho industrial, não somente na escola, mas em toda vida social". (GRAMSCI, 1990, p.240).

Vários autores, como Marx e Gramsci coadunam com a premissa sobre a indissociabilidade entre trabalho e educação, ou trabalho como princípio 
educativo. Em se tratando de ensino médio, o trabalho enquanto princípio educativo, nesta etapa, almeja proporcionar a compreensão da historicidade da produção científica e tecnológica, à proporção que os conhecimentos são desenvolvidos e apropriados pela sociedade. É nesse processo que o indivíduo se torna crítico, consciente do seu papel social, capaz de intervir positivamente em sua realidade, graças à formação humana integral.

Plantar as sementes de uma educação integrada, unitária, calcada nas bases da politecnia, visando à formação humana em todas as dimensões: físicas, mental, afetiva, estética, política e prática, combinando estudo e trabalho, apesar dessa discussão ser de longas datas, é um desafio atual. Nessa perspectiva, o trabalho visto como princípio educativo, ou seja, a partir dos pilares trabalho-educação é que as mudanças sociais podem ser materializadas e a subjugação dos trabalhadores superada, desde que haja 0 engajamento, sobretudo dos sujeitos da prática educativa docentes e discentes.

Nesse contexto, ressalta-se aqui a importância de práticas pedagógicas integradoras, contextualizadas, que não tenham como proposição a ação mercadológica, que não estejam pautadas só nas demandas de uma sociedade capitalista. Ademais, tais práticas precisam considerar os conhecimentos prévios dos educandos, reconhecê-los como sujeitos partícipes do processo histórico e que relacionem as suas condições reais com o mundo de forma consciente.

Deve-se acrescentar por fim, a importância do pensamento de Marx para além de Marx, baseado na concepção do próprio Marx, onde a realidade social é dinâmica, está em constante movimento. A referida realidade apresenta-se imbuída da historicidade que lhe é peculiar, onde sua dialética leva ao conhecimento através da dinâmica histórica do real, do objeto em todos os seus aspectos, em sua permanente relação com o sujeito. Em outras palavras, é no materialismo histórico dialético, cujas categorias fundantes são a totalidade, historicidade e contradição, que a luta de classes almeja a emancipação do proletariado, buscando superar o sistema capitalista, onde ter vale mais do que ser, o que compromete sobremaneira a dignidade humana dos menos favorecidos social e economicamente.

\section{REFERÊNCIAS}

ANITELLI, Fernando. Homem de papelão. Segundo ato, 2008. Disponível em: www.youtube.com.

CIAVATTA, Maria. O ensino integrado, a politecnia e a educação omnilateral: Por que lutamos? Trabalho \& Educação, Belo Horizonte, v. 23, n.1, p. 187205, jan. /abr. 2014. Disponível em: http://forumeja.org.br/go/sites/forumeja.org.br.go/files/Ciavatta_ensino_integra do_politecnia_educacao_omnilateral.pdf. Acesso em: 29 abr. 2019. 
FRIGOTTO, Gaudêncio. A polissemia da categoria trabalho e a batalha das ideias nas sociedades de classe. Revista Brasileira de Educação. v. 14, n. 40, p. 168-194, jan./abr. 2009.

FRIGOTTO, Gaudêncio; CIAVATTA, Maria. Perspectivas sociais e políticas da formação de nível médio: avanços e entraves nas suas modalidades.

Educ. Soc., Campinas, v. 32, n. 116, set. 2011.

KUENZER, Acácia. Da dualidade assumida à dualidade negada: o discurso da flexibilização justifica a inclusão excludente. Educ. Soc., Campinas, vol. 28, n. 100 - Especial, p. 1153-

1178, out. 2007. Disponível em: http://www.cedes.unicamp.br

KUENZER, Acácia. O Ensino Médio no plano nacional de educação 2011 2020: superando a década perdida? Educ. Soc., Campinas, v. 31, n. 112, jul-set. 2010.

RAMOS, Marise. Possibilidades e desafios na organização do currículo integrado. In: FRIGOTTO, Gaudêncio; CIAVATTA, Maria; RAMOS, Marise. Ensino Médio Integrado: concepções e contradições. São Paul: Cortez, 2005.

RAMOS, Marise. Ensino Médio Integrado: ciência, trabalho e cultura na relação entre educação profissional e educação básica. In: Moll, Jaqueline e colaboradores. Educação Profissional e Tecnológica no Brasil

Contemporâneo: desafios, tensões e possibilidades. Porto Alegre: Artmed, 2010. p. 42-56.

SAVIANI, Dermeval. Sobre a concepção de politecnia. Rio de Janeiro: Fiocruz, 1989.

SAVIANI, Dermeval. O choque teórico da politecnia. Educação, Trabalho e Saúde, Rio de Janeiro: EPSJV/FIOCRUZ, v. 1, p. 131-152, 2003.

SAVIANI, Dermeval. Trabalho e educação: fundamentos ontológicos e históricos. Revista Brasileira de Educação. v. 12, n. 34, p. 152-180, jan./abr. 2007.

MACHADO, Lucília. Ensino Médio e técnico como currículos integrados. In: Moll, Jaqueline e colaboradores. Educação Profissional e Tecnológica no Brasil Contemporâneo: desafios, tensões e possibilidades. Porto Alegre: Artmed, 2010. p. 80-95.

MANACORDA, Mário A. O princípio educativo em Gramsci. Porto Alegre: Artmed, 1990.

MARX. Karl. O capital. Vol. 1. São Paulo: Editora Nova Cultural Ltda., 1996.

MOURA, Dante Henrique; LIMA FILHO, Domingos Leite; Mônica Ribeiro.

Politecnia e formação integrada: confrontos conceituais, projetos políticos e contradições históricas da educação brasileira, v. 20, n. 63, p. 1057-1080, 
2015. Disponível em: http://www.scielo.br/pdf/rbedu/v20n63/1413-2478-rbedu20-63-1057.pdf. 